\title{
PROCESS DEVELOPMENT AND MECHANICAL PROPERTIES OF ALLOY U720LI FOR HIGH TEMPERATURE TURBINE DISKS.
}

\author{
R Couturier, H Burlet, S Terzi, S Dubiez, L Guetaz, G Raisson* \\ CEA Grenoble, DRT-DTEN-S3ME, Grenoble, France. \\ *Aubert \& Duval Holding, Direction Technique, Clermont-Ferrand, France
}

Keywords : Turbine disks, Powder metallurgy, Creep, High temperature nuclear Reactor

\begin{abstract}
Recent interest in nuclear high temperature reactor combined with a closed-cycle helium gas turbine provides the need for developing creep-resistant superalloys for the turbine disks and blades.

Superalloy Udimet $720 \mathrm{LI}^{\mathrm{TM}}$ has been selected as a candidate material to produce the large diameter turbine disks because of its high creep strength and industrial maturity. Studies were performed on both Powder Metallurgy (P/M) and Cast \& Wrought $(\mathrm{C} \& \mathrm{~W})$ billet samples. The effort was focussed on tailoring the microstructure to ensure a high creep strength and a good thermal stability. A new P/M process route has been developed to increase the grain size of the alloy and to ensure a good workability of P/M U720 with conventional forging route. The creep deformation and damage of $\mathrm{P} / \mathrm{M}$ Udimet 720 was analysed to develop a creep predictive model based on physical damage parameters.
\end{abstract}

\section{Introduction}

Recent advances in the design of turbomachinery, recuperators and magnetic bearings provide the potential to develop a High Temperature nuclear Reactor (HTR) cooled with helium and directly coupled to a high-efficiency helium turbine.

The specifications of the materials for the turbine are issued from the Gas Turbine Modular Helium Reactor (GT-MHR) design depicted in figure 1 [1]. This reactor is developed by an international consortium with a targeted $286 \mathrm{MWe}$ generation per module. The turbo-machine is a vertical assembly located in the central part of the power conversion unit and consists of the turbine (T), the low pressure and high pressure turbocompressors (LPC \& HPC), the electrical generator, recuperators and intercoolers.

There are a number of factors to be considered in the selection of materials for helium turbine components. Of prime interest are the creep and fatigue resistance, the thermal stability and the environmental resistance [2].

The gas turbine disks, with a maximum diameter about $1.3 \mathrm{~m}$, are expected to work at a maximum temperature of about $700^{\circ} \mathrm{C}$ during 60000 hours without significant maintenance. Since a high creep resistance is required, the processing route and heat treatments will aim at achieving a coarse grained microstructure with stabilized gamma prime $\left(\gamma^{\prime}\right)$ precipitation.

We have selected U720LI as the most promising grade considering its creep strength around $700^{\circ} \mathrm{C}$ and its industrial maturity. Two process routes were investigated in parallel.

The first one which is the most widespread method to manufacture turbine disk blanks is the "cast \& wrought" route.

${ }^{\mathrm{TM}}$ Udimet is a registered trademark of Special Metals Corporation.

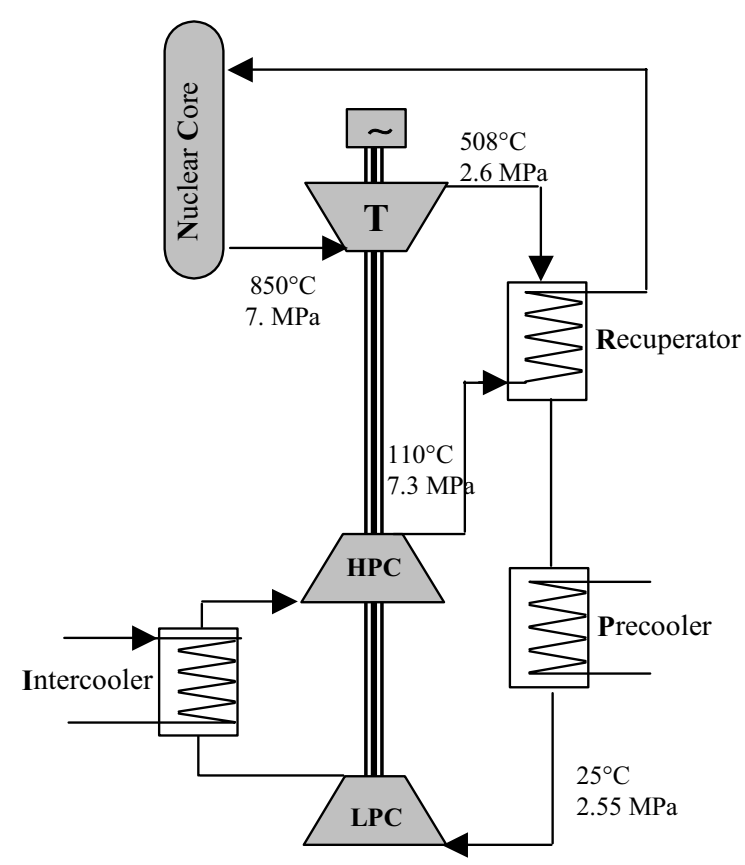

Figure 1 : Schematic representation of the Gas Turbine Modular Helium Reactor design.

Processing of HTR disks requires the production of large ingots, and difficulties are expected with the triple melt process, related to a risk of chemical macrosegregations.

Forging is also critical since the workability of U720 for such large components has never been demonstrated before. Forged U720LI is known to exhibit a very rapid and non uniform graincoarsening behaviour, which also makes the heat treatment step challenging. Nethertheless, rough estimates of process parameters (ingot size, press capacity) showed that the production of HTR disks should be feasible in a near future [3].

The alternative process route which was considered is based on Powder Metallurgy (P/M). One of the main advantages of this process is that it is possible to manufacture a blank with a geometry and size close to those of the final product, resulting in a reduction of metal loss during machining. Moreover, the $\mathrm{P} / \mathrm{M}$ route allows the production of very homogeneous material, resulting in better defect detection capability by ultrasonic inspection. However, this process suffers from other drawbacks such as the possible pollution by ceramic inclusions issued from the powder atomisation which may act as fatigue crack initiation sites, and the formation of precipitates at the Prior Particle Boundaries (PPB). Because of the presence of small precipitates at the PPB which pin the grain boundaries, one can 
the P/MU720 LI grain size is roughly limited to the average size of the powder particles [4]. Because of the fine grained microstructure, the behaviour of P/M U720 is usually not suitable for high temperature applications $\left(>650^{\circ} \mathrm{C}\right)$ when good creep and crack propagation resistance are required.

The PPBs have also a detrimental effect on the workability of as-HIPed material, and initial attempts to use conventional forging routes were unsuccessful [5]. Therefore, high-cost extrusion processes were developed to ensure the minimum forging ratios imposed for critical applications [6].

\section{Experimental Procedures}

Laboratory experiments were conducted to study the microstructure and mechanical properties of $\mathrm{C} \& \mathrm{~W}$ and HIPed U720LI

The C\&W material was produced by Aubert\&Duval as a pancake with $32 \mathrm{~cm}$ diameter and $8 \mathrm{~cm}$ height. The production route includes a triple melt elaboration followed by fine-grain billetizing, ultrasonic inspection and conventional forging. The final heat treatment includes a supersolvus step to insure the grain coarsening.

For P/M material, low carbon steel containers (with diameters ranging from 63 to $120 \mathrm{~mm}$ ) were filled with 230 mesh argon atomised powder, degassed and sealed before consolidation with CEA or Aubert\&Duval HIP facility.

Two HIP cycles were investigated : the conventional HIP cycle $1100^{\circ} \mathrm{C} / 1400 \mathrm{bar} / 3 \mathrm{~h}$ (denoted $\left.H I P-A\right)$ and a specific HIP cycle developed to allow grain coarsening (denoted $H I P-B)$ [7]. HIP$B$ cycle includes a first subsolvus step at $\left\{\mathrm{T} \gamma_{\text {solvus }}-15^{\circ} \mathrm{C}\right\}$ under low pressure $(<10 \mathrm{MPa})$ followed by a second supersolvus step at $\left\{\mathrm{T} \gamma_{\text {solvus }}+15^{\circ} \mathrm{C}\right\}$ under high pressure $(>100 \mathrm{MPa})$. HIP-A material was then heat treated with either HS (High Strength) or CR (Creep Resistant) heat treatments [8]. HIP-B material has been subjected to a specific supersolvus heat treatment after HIPing, followed by a slightly modified CR ageing sequence [7].

The specific chemistry and heat treatments of the U720LI materials investigated in this program are listed in table I and II.

Table I : Chemistry of the U720LI materials studied (w \%).

\begin{tabular}{|l|c|c|c|c|c|c|c|c|c|c|}
\hline & Cr & Co & Ti & Al & Mo & W & Zr & C & B & Ni \\
\hline
\end{tabular}

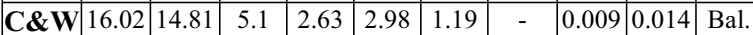
\begin{tabular}{|l|l|l|l|l|l|l|l|l|l|l|}
\hline $\boldsymbol{H I P}-\boldsymbol{A}$ & 16.2 & 15.3 & 5.18 & 2.47 & 3.06 & 1.33 & 0.039 & 0.023 & 0.018 & Bal. \\
\hline
\end{tabular} \begin{tabular}{|l|l|l|l|l|l|l|l|l|l|l|}
\hline HIP-B & 16.4 & 15.3 & 5.04 & 2.49 & 3.06 & 1.3 & 0.035 & 0.012 & 0.015 & Bal. \\
\hline
\end{tabular}

Table II : Heat treatments applied to U720LI materials.

\begin{tabular}{|l|l|l|}
\hline \multicolumn{1}{|c|}{ Solution treatment } & Aging treatment \\
\hline $\mathbf{C \& W}$ & $1157^{\circ} \mathrm{C} / 4 \mathrm{~h} /$ Air Cooled & $845^{\circ} \mathrm{C} / 24 \mathrm{~h} / \mathrm{AC}$ \\
& $1090^{\circ} \mathrm{C} / 4 \mathrm{~h} /$ Oil Quenched & $760^{\circ} \mathrm{C} / 16 \mathrm{~h} / \mathrm{AC}$ \\
\hline $\boldsymbol{H I P}-\boldsymbol{A}$ & $\mathbf{H S}:$ & $\mathbf{H S}:$ \\
& $1110^{\circ} \mathrm{C} / 4 \mathrm{~h} /$ cooled at $60^{\circ} \mathrm{C} / \mathrm{min}$ & $650^{\circ} \mathrm{C} / 24 \mathrm{~h} / \mathrm{AC}$ \\
& $\mathbf{C R}:$ & $760^{\circ} \mathrm{C} / 16 \mathrm{~h} / \mathrm{AC}$ \\
& $1170^{\circ} \mathrm{C} / 4 \mathrm{~h} /$ cooled at $60^{\circ} \mathrm{C} / \mathrm{min}$ & $845^{\circ} \mathrm{C} / 24 \mathrm{~h} / \mathrm{AC}$ \\
& $1080^{\circ} \mathrm{C} / 4 \mathrm{~h} /$ cooled at $60^{\circ} \mathrm{C} / \mathrm{min}$ & $760^{\circ} \mathrm{C} / 16 \mathrm{~h} / \mathrm{AC}$ \\
& & \\
\hline $\boldsymbol{H I P}-\boldsymbol{B}$ & Specific supersolvus cycle + & $845^{\circ} \mathrm{C} / 24 \mathrm{~h} / \mathrm{AC}$ \\
& $1110^{\circ} \mathrm{C} / 4 \mathrm{~h} /$ cooled at $60^{\circ} \mathrm{C} / \mathrm{min}$ & $760^{\circ} \mathrm{C} / 16 \mathrm{~h} / \mathrm{AC}$ \\
\hline
\end{tabular}

The microstructure was examined using optical microscopy and Transmission Electron Microscopy (TEM) techniques. Creep tensile tests have been performed under air in the range $650^{\circ} \mathrm{C}$ $750^{\circ} \mathrm{C}$ on cylindrical specimens $(\phi 4 \mathrm{~mm}$, gage length $20 \mathrm{~mm})$. Stress range applied to the specimens was selected to reach fracture between 10 to $5000 \mathrm{~h}$. Creep tests have been conducted under constant load. Tensile tests have been performed at a strain rate of $5.10^{-4} \mathrm{~s}^{-1}$ with the same specimen geometry.

Workability was evaluated by performing high temperature torsion tests at various strain rates and temperatures and by examining the microstructure after straining.

\section{Microstructural analysis}

Metallography performed on the C\&W and HIPed U720 samples revealed a strong dependence of grain size and gamma prime distribution with process route.

The table III compares the microstructural features of the samples issued from powder and conventional metallurgy.

Table III : Microstructural parameters obtained on C\&W and P/M U720 LI.

\begin{tabular}{|c|c|l|}
\hline & $\begin{array}{c}\text { Average } \\
\text { ASTM grain size }\end{array}$ & $\begin{array}{c}\text { Average } \\
\boldsymbol{\gamma} \text { diameters }(\mathbf{n m})\end{array}$ \\
\hline $\mathbf{C \& W}$ & $\begin{array}{c}\text { (large grains) } \\
10 \text { (small grains) }\end{array}$ & $\begin{array}{l}\text { Primary }: 2500 \\
\text { Secondary }: 400 \\
\text { Tertiary }: 50\end{array}$ \\
\hline HIP-A + HS & 12 & $\begin{array}{l}\text { Primary }: 450 \\
\text { Secondary }: 40 \\
\text { Tertiary }: 10\end{array}$ \\
\hline HIP-A + CR & \multirow{2}{*}{$\begin{array}{l}\text { Primary }: \text { none } \\
\text { Secondary }: 300 \\
\text { Tertiary }: 30\end{array}$} \\
\hline HIP-B & 5 & $\begin{array}{l}\text { Primary : none } \\
\text { Secondary }: 500 \\
\text { Tertiary }: 20-100\end{array}$ \\
\hline
\end{tabular}

For C\&W U720, the grain size is heterogeneous, with bands of coarse grains $(\phi 500 \mu \mathrm{m})$ separated by areas where the grain size does not exceeds $50 \mu \mathrm{m}$ (figure 2). This duplex grain size is linked to segregations during ingot solidification. During forging of the fine grained U720 billet, primary gamma prime precipitates are distributed within the material with a non uniform localization. Moreover, all the primary $\gamma^{\prime}$ have not the same precise dissolution temperature, as a result of chemical segregations issued from the ingot remelting and not fully homogenised during conversion. When the supersolvus heat treatment is applied at $1157^{\circ} \mathrm{C}$ (just above $\mathrm{T} \gamma_{\text {solvus }}^{\prime}$ measured at $1153^{\circ} \mathrm{C}$ for this alloy), the $\gamma$ grains are coarsened in the regions where the $\gamma^{\prime}$ are dissolved, but locally the $\gamma$ grains are pinned by non-dissolved $\gamma^{\prime}$.

The observed grain size heterogeneity on C\&W U720 indicates that the control of microstructure will be a challenge for future large HTR disks, where grain size and $\gamma^{\prime}$ distribution variations are expected through the thickness.

TEM examinations on C\&W U720 have shown an homogeneous distribution of secondary and tertiary $\gamma^{\prime}$ precipitates within the disk. Primary $\gamma^{\prime}$ and grain boundaries are often decorated with $\mathrm{M}_{23} \mathrm{C}_{6}$ type carbides.

These microstructural observations demonstrate that achieving a uniform and controlled grain size on conventionally forged 
U720 will require additional studies for HTR disks as the temperature window to achieve a uniform grain coarsening is small.

For P/M U720 Hiped with a conventional cycle $(H I P-A)$, the austenitic grain size is roughly limited to the average size of the powder particles, even if a supersolvus heat treatment is applied. This grain growth impingement can be attributed to the presence of finely dispersed precipitates at the PPB that pin the grain boundaries during the supersolvus step.

After the HIP-A consolidation cycle, the gamma prime distribution is directly linked to the solutioning and ageing treatments. After HS heat treatment, there are three different types of $\gamma^{\prime}$ (figure 3a) : primary $\gamma^{\prime}$ formed during HIPing, with an average diameter of $450 \mathrm{~nm}$, then secondary and tertiary $\gamma^{\prime}$ nucleated during cooling after solutioning treatment and coarsened during ageings, with respective average diameters of $40 \mathrm{~nm}$ and $10 \mathrm{~nm}$. After CR heat treatment, only two types of $\gamma^{\prime}$ are formed during cooling (figure $3 b$ ) : the secondary $\gamma^{\prime}$ with a diameter of $300 \mathrm{~nm}$ and a tertiary ones with a diameter of 30 nm.

For P/M U720 produced with $H I P-B$ condition, figure 4 shows that the grain size is higher than with $H I P-A$, and the grain boundaries have overcome the precipitates at the PPBs. At the scale of TEM, the gamma prime distribution appears homogeneous with a higher density of tertiary $\gamma^{\prime}$ than for HIP-A material with $\mathrm{CR}$ heat treatment. Grain boundaries are often decorated with $\mathrm{M}_{23} \mathrm{C}_{6}$ type carbides.

The HIP-B material demonstrates that the powder metallurgy route allows the production of P/M U720LI with controlled coarse grain size required for high temperature applications where creep is a predominent design criteria.
HIP $B$ process uses a specific HIP cycle as proposed by Davidson [9] where a first stage is dedicated to attenuate the precipitation of segregated elements on the powder particule surface. A second stage ensure the full compaction of the powder and the displacement of grain boundaries beyond the PPBs. A supersolvus post-HIP heat treatment is then applied to ensure grain growth, with a final grain size tailored by the temperature level and duration of this treatment.

When compared to recent published studies on grain enlargement on $\mathrm{P} / \mathrm{M} \mathrm{U} 720$, the $H I P-B$ process offers several advantages :

- HIP $B$ material is not subjected to a sub-solidus heat treatment like in [5] and therefore the grain growth is possible while maintaining a fine gamma prime microstructure, and the risk of incipient melting is eliminated.

- HIP $B$ microstructure consists of grains that are not pinned by PPB precipitates, as it is the case for coarse grain $\mathrm{P} / \mathrm{M}$ U720 obtained by a simple post-HIP supersolvus heat treatment [4]. The well known detrimental effects of PPB precipitates on hot ductility are therefore expected to disappear, allowing a better workability on conventional press conversion equipment. In fact, it is expected that $H I P-B$ U720 will not require extrusion or isothermal forging usually applied.

- Thermally induced porosity is not likely to appear during the elaboration sequence, as the final densification stage is performed at high temperature (supersolvus).
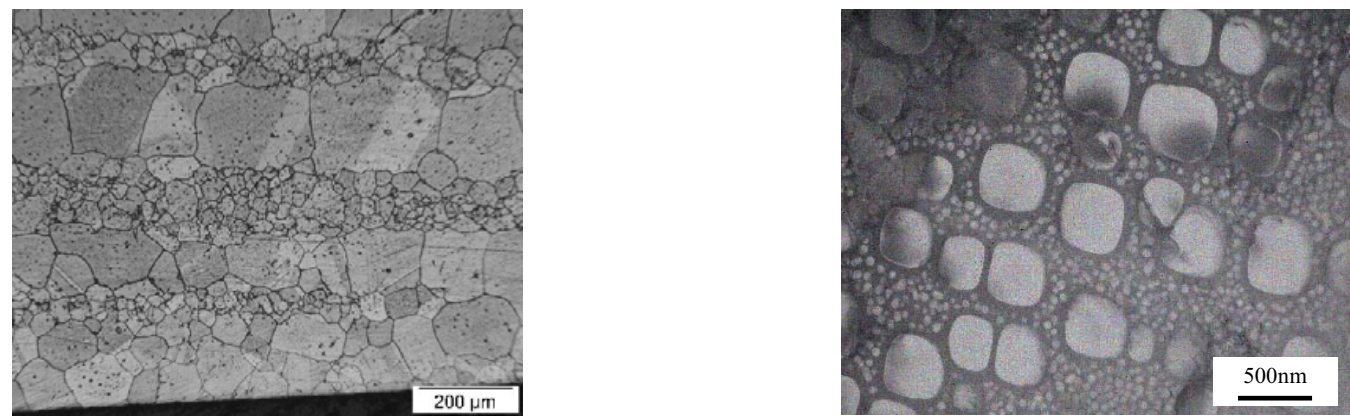

Figure 2: Typical microstructure and gamma prime distribution observed by optical metallography and TEM for C\&W U720.
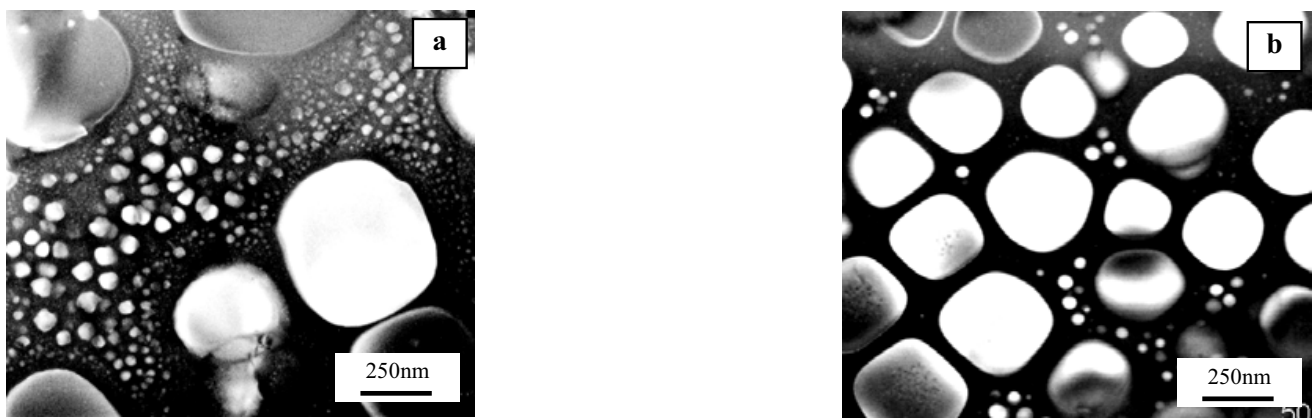

Figure 3 : Typical gamma prime microstructure observed by TEM for P/M U720 after $H I P$ - $A$ with HS (a) and CR (b) heat treatments. 

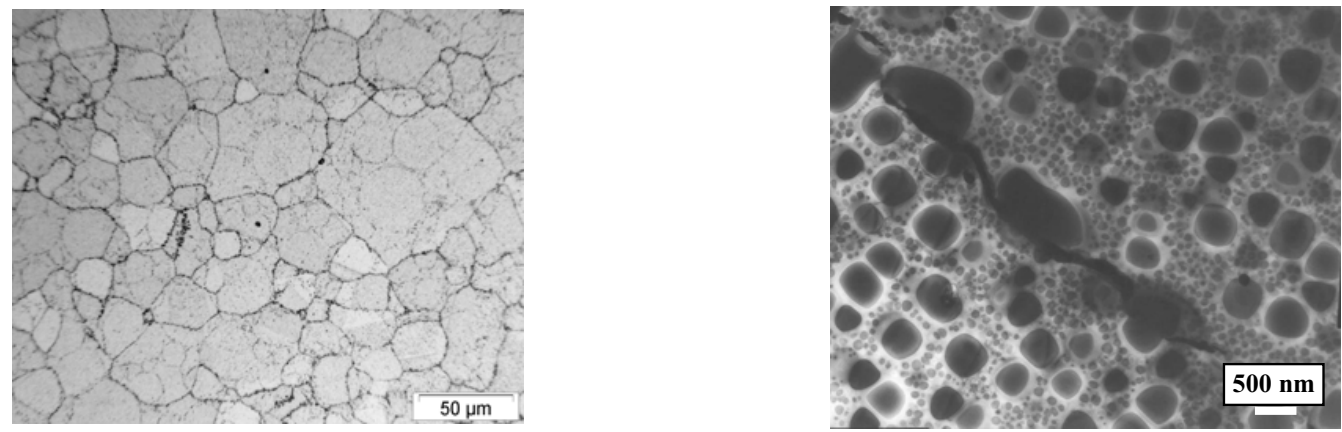

Figure 4 : Typical microstructure and gamma prime distribution observed by optical metallography and TEM for P/M HIP-B U720.

\section{Tensile properties}

Since the purpose of this investigation was to examine the effects of process parameters on microstructure and mechanical properties, tensile and creep tests have been conducted on both $\mathrm{C} \& \mathrm{~W}$ and $\mathrm{P} / \mathrm{M}$ Udimet 720 heat treated with a supersolvus step.

Tensile tests have been performed at $20^{\circ} \mathrm{C}, 650^{\circ} \mathrm{C}$ and $750^{\circ} \mathrm{C}$, and average tensile results of duplicate tests are presented in table IV.

The tensile strength of the alloys developed in this study are not as high as usually measured on fine grained Udimet 720 [8]. The objective is indeed to focus more on creep properties, thermal stability and workability of the materials to produce large disks for long term applications.
The lower high temperature tensile yield strengths offered by $\mathrm{P} / \mathrm{M} H I P-A$ material compared to $\mathrm{C} \& \mathrm{~W}$ and $H I P-B$ materials could be attributed to the lower density of tertiary gamma prime precipitates observed in figure 3 . It has been shown [10] that the tensile deformation is due to an Orowan mechanism with dislocations forming loops around the $\gamma^{\prime}$ precipitates. Therefore, a high density of tertiary $\gamma^{\prime}$ leads to an increase of the yield strength. The austenitic grain size appears to have a small effect on yield strength for U720 LI at high temperature. It should be noticed that the high tensile strength observed on $\mathrm{C} \& \mathrm{~W}$ grade is the direct result of a high cooling rate after subsolvus solutionning, as a result of oil quenching. For future HTR disks, we can expect that the lower cooling rates applied for large disks will lead to a slight decrease in tensile properties.

The tensile tests have shown two interesting trends in the behaviour of $H I P-B$ material when the test temperature is increased : the drop of yield strength with temperature for $H I P$ $B$ is less pronounced than for $H I P-A$ material and the tensile ductility is much higher at $650^{\circ} \mathrm{C}$ and $750^{\circ} \mathrm{C}$.

Table IV : C\&W and Supersolvus heat treated P/M Udimet 720 tensile data.

\begin{tabular}{|c|c|c|c|c|}
\hline $\begin{array}{c}\text { Temperature } \\
\left({ }^{\circ} \mathrm{C}\right)\end{array}$ & Property & $C \& W$ & $H I P-A+C R$ & HIP-B \\
\hline \multirow{3}{*}{20} & $\begin{array}{c}0.2 \% \text { Y.S. } \\
\text { (MPa) }\end{array}$ & 1000 & 950 & 930 \\
\hline & $\begin{array}{l}\text { U.T.S } \\
\text { (MPa) }\end{array}$ & 1395 & 1445 & 1380 \\
\hline & $\%$ El. & 17 & 21 & 14 \\
\hline \multirow{3}{*}{650} & $\begin{array}{c}0.2 \% \text { Y.S. } \\
(\mathrm{MPa})\end{array}$ & 895 & 830 & 865 \\
\hline & $\begin{array}{l}\text { U.T.S } \\
(\mathrm{MPa})\end{array}$ & 1210 & 1170 & 1225 \\
\hline & $\%$ El. & 24 & 18 & 38 \\
\hline \multirow{3}{*}{750} & $\begin{array}{c}0.2 \% \text { Y.S. } \\
(\mathrm{MPa})\end{array}$ & 875 & 770 & 870 \\
\hline & $\begin{array}{l}\text { U.T.S } \\
\text { (MPa) }\end{array}$ & 980 & 890 & 950 \\
\hline & $\%$ El. & 31 & 7 & 33 \\
\hline
\end{tabular}




\section{Creep properties}

Creep rupture tests have been performed in air on both $\mathrm{C} \& \mathrm{~W}$ and HIPped Udimet 720. In order to compare the creep strengths of the three supersolvus heat treated materials analysed in this study $(H I P-A+\mathrm{CR}, H I P-B$ and $\mathrm{C} \& \mathrm{~W})$, their creep rupture properties are synthesized in figure 5 .

The Larson-Miller representation shows that the C\&W U720 has the best creep properties. At high stress (corresponding to low test temperature or rupture time), both $\mathrm{C} \& \mathrm{~W}$ and $H I P-A$ materials have equivalent creep resistance, despite their microstructural differences in grain size and tertiary gamma prime density. When the applied stress decreases, the $C \& W$ grade shows a much better creep resistance than the HIP-A $\mathrm{P} / \mathrm{M}$ material.

This indicates that the grain size is the controlling factor for creep strength at low stresses (or high temperatures) and for long term creep. At high stresses, intra-granular microstructure is responsible for the creep strength.

It is also noticeable that the $H I P-B$ material shows an enhanced creep strength compared to $H I P-A$ material. Even if only preliminary results were obtained for $H I P-B$ material, we can expect that the performance of this coarse grained $\mathrm{P} / \mathrm{M}$ grade will compare with the properties of conventional $\mathrm{C} \& \mathrm{~W}$ Udimet 720 .

In order to develop an improved understanding of the different creep behaviour between $H I P-A$ and $H I P-B$ materials, the fracture surfaces of both grades tested at $750^{\circ} \mathrm{C}$ were observed by SEM. For HIP-A U720 the fracture is composed of intergranular zones and inter-particular zones, showing that the contiguity between PPBs and grain boundaries results in some powder particle decohesion during creep. For $H I P-B$ material the fracture surface is fully inter-granular and no particle decohesion has been observed.

\section{Forgeability of P/M HIP-B Coarse grain Udimet 720}

The first evaluation of mechanical properties of HIP-B U720 have demonstrated the interest of this grade which showed improved high temperature properties compared to conventional HIP-A material.

If this grade is used for long term applications as large turbine disks, the workability of $H I P-B$ U720 has to be assessed with two objectives :

- to determine the conditions for conventional forging, in terms of billet temperature, strain rate and allowable reduction.

- to ensure the possible recovery of an homogeneous and controlled coarse grained microstructure after forging.

As a first evaluation of hot workability of $H I P-B$ grade, high temperature torsion tests have been perfomed at Aubert\&Duval at various temperature and strain rates.

This evaluation has allowed to determine process parameters for conventional forging. It has been demonstrated that a proper selection of temperature and strain rate resulted in a controlled recrystallisation during deformation. Metallographic analysis of deformed torsion specimens have shown that the coarse grained microstructure is retained after deformation [11].

These encouraging results will soon be used to forge laboratory scale trial disks of HIP $B$ U720.

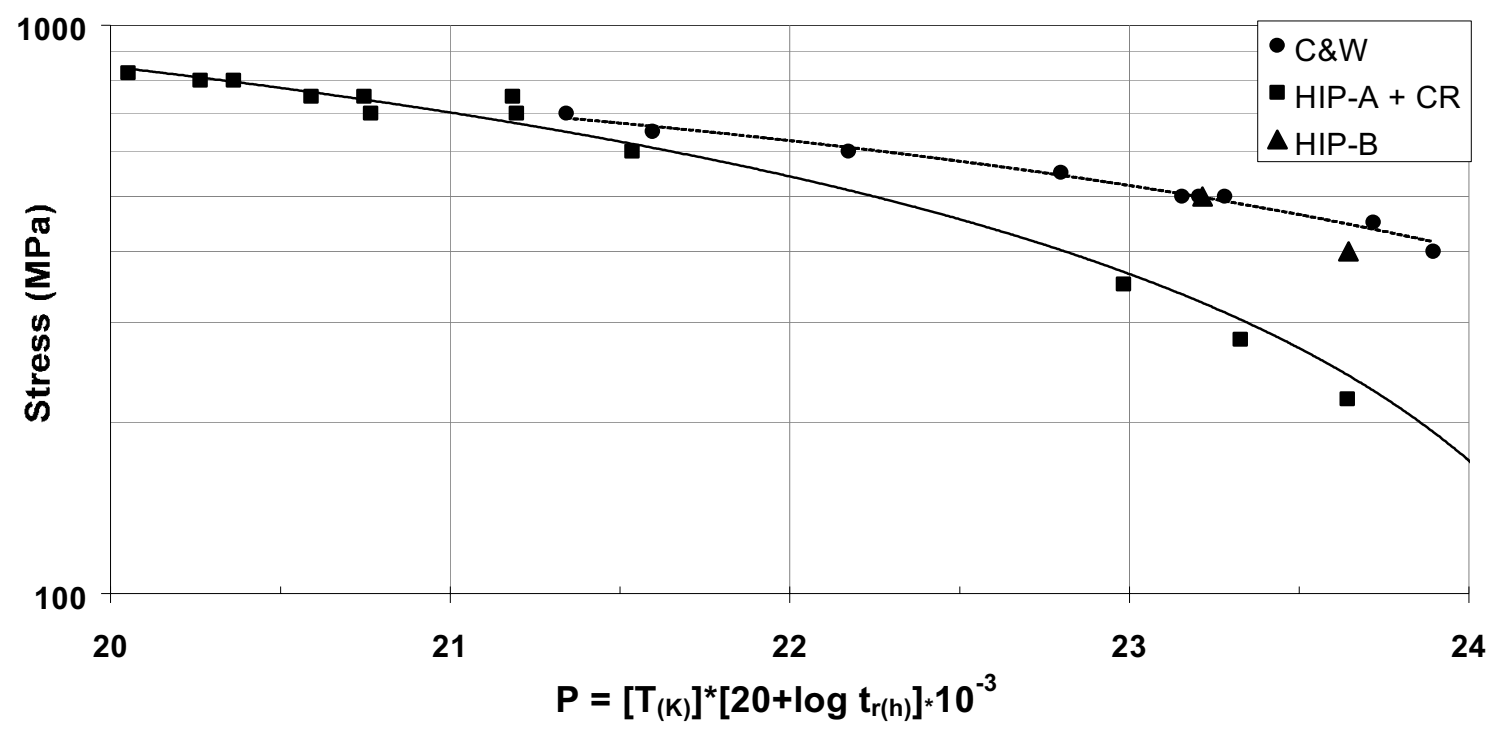

Figure 5 : Larson-Miller creep rupture plot of $\mathrm{C} \& \mathrm{~W}, H I P-A+\mathrm{CR}$ and $H I P-B$ Udimet 720 grades. 


\section{Creep behaviour and modelling of $\mathrm{P} / \mathrm{M} H I P-A$ U720}

When analysing the creep curves of P/M U720, we observe a creep rate continually increasing with time, without any noticeable "steady" creep regime. It is therefore a major concern to develop predictive models describing the apparent tertiary creep of this superalloy in order to establish the proper design rules.

For this purpose, the creep behaviour of conventionally processed HIP-A U720 was investigated by conducting deformation creep tests from $650^{\circ} \mathrm{C}$ to $750^{\circ} \mathrm{C}$ on two microstructures obtained after $\mathrm{HS}$ or $\mathrm{CR}$ heat treatments, analysing the deformation and damage mechanisms, and developing a creep predictive model based on McLean and Dyson approach [10].

At $650^{\circ} \mathrm{C}$, the creep curves of the HS microstructure show a transition directly from primary to "apparent" tertiary creep with no obvious steady state (figure 6). On the contrary, the creep curves of the $\mathrm{CR}$ microstructure show the classical three creep stages.

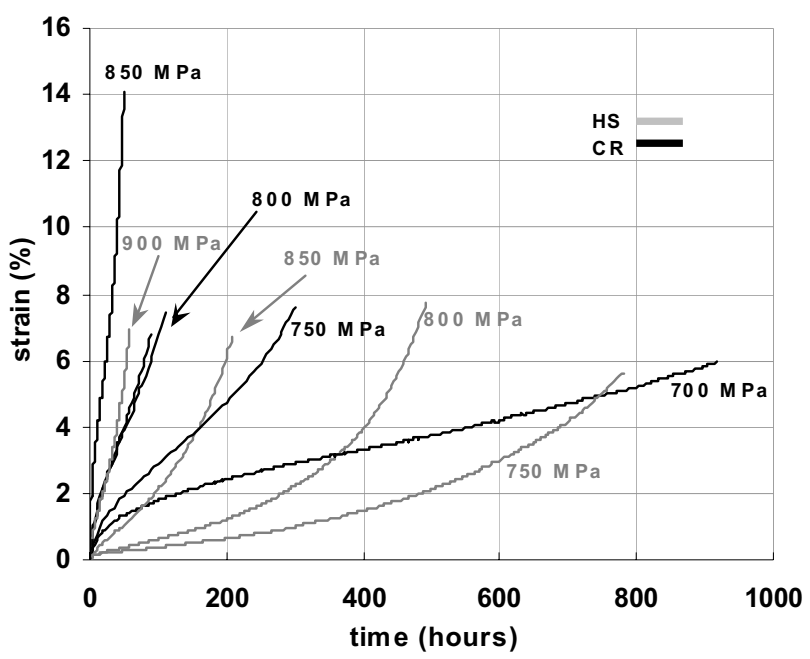

Figure 6 : Creep curves at $650^{\circ} \mathrm{C}$ of the $\mathrm{P} / \mathrm{M} H I P-A$ Udimet 720 after HS and CR heat treatments.

To understand why the creep rate quickly increases after the minimum creep rate, four different hypotheses of softening mechanisms were investigated : early damage of the specimen, degradation of microstructure related to ageing, increase of the true stress during creep deformation, and interactions between dislocations and $\gamma^{\prime}$.

\section{Early damage by micro-cracking and cavity nucleation}

This hypothesis does not seem relevant at $650^{\circ} \mathrm{C}$, as only few micro-cracks are observed very close to the fracture surface on longitudinal cross-sections of broken specimens. At $750^{\circ} \mathrm{C}$, intergranular cavities and cracks are observed in the bulk of the specimen at failure. A specific test was therefore conducted to show whether the observed damage is responsible for the observed softening. A creep test $\left(750^{\circ} \mathrm{C} / 280 \mathrm{MPa}\right)$ has been stopped at $2 / 3$ of the creep life. Then, the microstructure has been restored by applying the full HS heat treatment cycle to the specimen (under vacuum), and the creep test was started again and run until rupture under the same conditions. The behaviour of this rejuvenated specimen looked like the one of the virgin material. This suggests that the specimen creep rate is not influenced by cracks or voids after $2 / 3$ of creep life, when softening is already observed.

\section{Degradation of the microstructure related to ageing}

Creep softening of superalloy is often related to ageing as $\gamma$ ' coarsen during the test. At $650^{\circ} \mathrm{C}$, TEM observations have shown that ageing up to $5000 \mathrm{~h}$ has no measurable effect on $\gamma^{\prime}$ precipitate size for both HS and CR microstructures.

Therefore, ageing is not responsible for the different creep behaviours of $\mathrm{HS}$ and $\mathrm{CR}$ materials at $650^{\circ} \mathrm{C}$.

Increase of true stress during creep deformation

In this work, creep tests were not conducted under constant stress, but under constant load. The applied true stress thus increases as the strain increases and the section decreases. The true stress is defined as $\sigma=\sigma_{0} \exp (\varepsilon)$, with initial stress $\sigma_{0}$ and true strain $\varepsilon$.

As proposed by Maldini [12], the true strain rate of the creep tests shown on figure 6 are plotted in figure 7 as a function of true stress. The decrease of the strain rate corresponds to the primary stage, then the increase of the strain rate corresponds to the secondary and tertiary stages. On this representation, creep

rate using Norton stress dependence law, as $\dot{\varepsilon} \propto \sigma^{\mathrm{n}}$, with Norton coefficient $\mathrm{n}$ adjusted to the experimental steady-state or minimum creep rate was drawn as dashed lines.

For CR microstructure, $\mathrm{n}$ is 20 for the applied stress range. But a single $\mathrm{n}$ value cannot describe HS microstructure stress dependence at all stresses. Thus, for $850 \mathrm{MPa}$ and $900 \mathrm{MPa}, \mathrm{n}$ is 24 and for $600 \mathrm{MPa}, 750 \mathrm{MPa}$ and $800 \mathrm{MPa}, \mathrm{n}$ is 12 . The plot of figure 7 enables to emphasize the two different kinds of creep behaviour. For CR microstructure, after primary stage, curves fall on the Norton's law plot. This means that the increase of the strain rate observed on figure 6 corresponds to a steady-state stage, and that acceleration of creep is only due to the increase of the true stress.

HS microstructure behaviour differs from high stresses to low stresses. At $850 \mathrm{MPa}$ and $900 \mathrm{MPa}$, the apparent tertiary stage is linked to the stress increase during the creep test, as observed for $\mathrm{CR}$ microstructure. In contrast at $600 \mathrm{MPa}, 750 \mathrm{MPa}$ and $800 \mathrm{MPa}$, strain rate increases more quickly than Norton's law prediction. For this stress range, an additional damage parameter is required to describe the softening of the alloy during creep. 


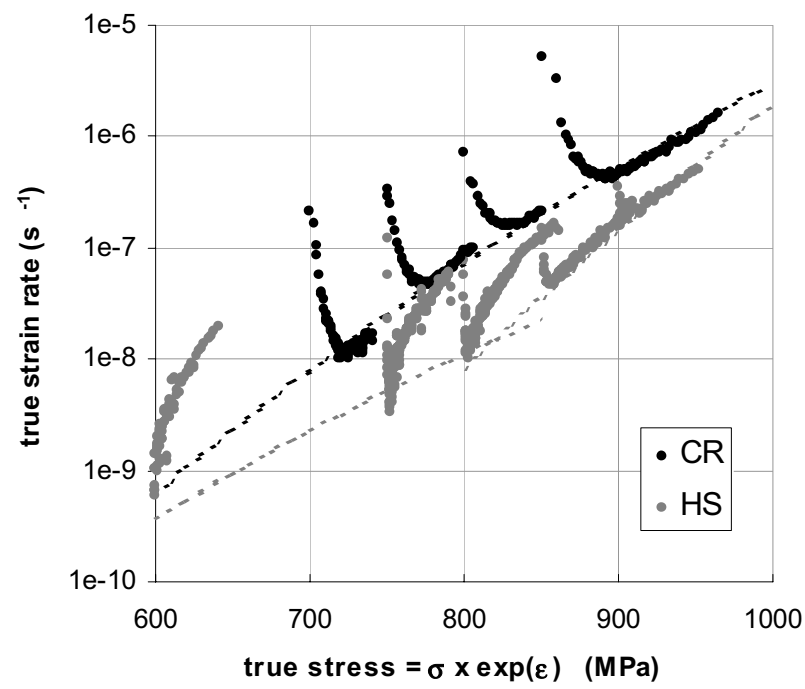

Figure 7 : True strain rate as a function of the true stress for $650^{\circ} \mathrm{C}$ creep tests. The rates obtained from Norton law are also drawn as dashed lines.

\section{Interactions between dislocations and $\gamma$}

TEM analysis of crept specimen strained at $1 \%$ under $750 \mathrm{MPa}$ at $650^{\circ} \mathrm{C}$ show large stacking faults inside the $\gamma^{\prime}$ for U720 HS (figure 8a) and dislocation loops around the $\gamma^{\prime}$ for the U720 CR (figure 8b).

These observations indicate that the difference of creep behaviour at $750 \mathrm{MPa}$ is related to different deformation mechanisms: U720 CR $\gamma^{\prime}$ are by-passed by an Orowan mechanism whereas U720 HS $\gamma^{\prime}$ are sheared. These two mechanisms, already observed in other recent PM nickel-based superalloys $[13,14]$, seem to be strongly related to the presence of tertiary $\gamma^{\prime}$. The large $\gamma$ corridors observed in U720 CR promote an Orowan mechanism whereas the presence of tertiary $\gamma^{\prime}$ in U720 HS decreases the corridor width and promotes a shearing mechanism. According to the previous investigation, Orowan mechanism observed in U720 CR could be connected to a classical behaviour with a steady state stage, whereas shearing observed in U720 HS could be connected to a softening mechanism.

However, stress-assisted tertiary stage also appears at high stress for U720 HS and could thus be related to Orowan mechanism as for U720 CR. This has been confirmed by TEM observations of interrupted tensile U720 HS specimen showing Orowan loops around $\gamma^{\prime}$. The deformation mechanisms hence depend on the stress level. The transition between the two mechanisms should be the Orowan stress.

Precipitate shearing is often considered as a softening mechanism and form many dislocations along the same gliding plane. In U720 HS crept at $650^{\circ} \mathrm{C}$, no localisation of the slip has been observed. The complex stacking faults left by the first shearing dislocation inside the $\gamma^{\prime}$ probably do not make the glide on the same plane easier. Then, $\gamma$ ' shearing mechanism would not directly explain the creep softening.

The reason for observed creep softening could be an increase of mobile dislocation density during the creep test. This could be ascribed to the low dislocation velocity during shearing [10].

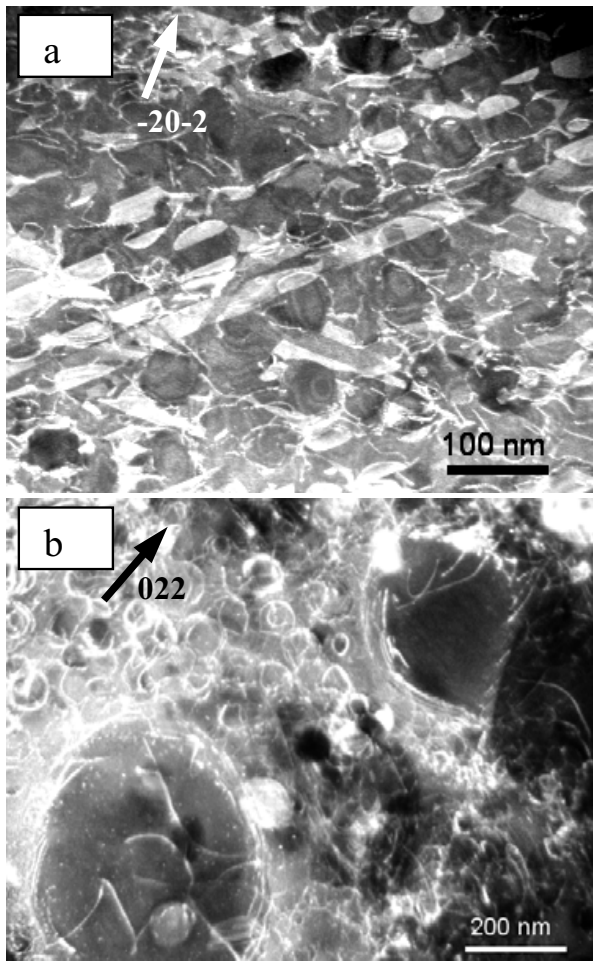

Figure 8 : Dislocation structure in the Udimet $720 \mathrm{HS}$ (a) and Udimet 720 CR (b) (TEM weak-beam) in interrupted specimen crept after $1 \%$ strain under $750 \mathrm{MPa}$ at $650^{\circ} \mathrm{C}$.

\section{Creep modelling}

McLean and Dyson proposed a specific model to predict creep behaviour of complex alloy: a physically based continuum creep damage model with internal state variables which relates the strain rate response to the applied stress [15]. The equation of the chosen model results in a set of a hardening parameter $\mathrm{H}$ to describe the primary creep stage and a parameter $D_{d}$ to describe the multiplication of the mobile dislocation density, only for U720 HS at low stress :

$$
\begin{aligned}
& \dot{\varepsilon}=\frac{\dot{\varepsilon}_{0}}{1-\mathrm{D}_{\mathrm{d}}} \sinh \left(\frac{\sigma(1-\mathrm{H})}{\sigma_{0}}\right) \\
& \dot{\mathrm{H}}=\frac{\mathrm{h}^{\prime}}{\sigma}\left(1-\frac{\mathrm{H}}{\mathrm{H}^{*}}\right) \dot{\varepsilon}, \dot{\mathrm{D}}_{\mathrm{d}}=\mathrm{C}\left(1-\mathrm{D}_{\mathrm{d}}\right)^{2} \dot{\varepsilon}
\end{aligned}
$$

with characteristic rate $\dot{\varepsilon}_{0}$, true stress $\sigma$, cinematic back stress $\sigma_{0}$, normalized saturation stress $H^{*}$, effective Young's modulus h', and a material constant $\mathrm{C}$. Best parameter sets identified are given in table $\mathrm{V}$.

For U720 CR and U720 HS creep at high stress, both having a classical behavior, no damage parameter is required to describe the full creep curve. For U720 HS at low stress, softening is modeled by an increase of mobile dislocation density.

Figure 9 shows experimental creep curves compared with the results of the simulation, using the proposed model : creep behaviour of U720 CR and U720 HS at $850 \mathrm{MPa}$ and $900 \mathrm{MPa}$ 
is fairly well predicted, but creep behaviour of U720 HS at 750 $\mathrm{MPa}$ and $800 \mathrm{MPa}$ has to be further analyzed. The implementation of a more physical softening parameter involving the evolution of mobile dislocation density appears interesting.

Table V. Model parameter set for HIP-A U720 HS and CR used to generate the curves in figure 9 .

\begin{tabular}{cccccc}
\hline & $\dot{\varepsilon}_{0}(\mathrm{~s}-1)$ & $\sigma_{0}(\mathrm{MPa})$ & $\mathrm{h}^{\prime}(\mathrm{MPa})$ & $\mathrm{H}^{*}$ & $\mathrm{C}$ \\
\hline $\mathrm{CR}$ & $1.710^{-13}$ & 34.0 & 58835 & 0.08 & 0 \\
\hline $\mathrm{HS}$ & $1.810^{-13}$ & 33.7 & 58357 & 0.1 & 1600 \\
\hline
\end{tabular}
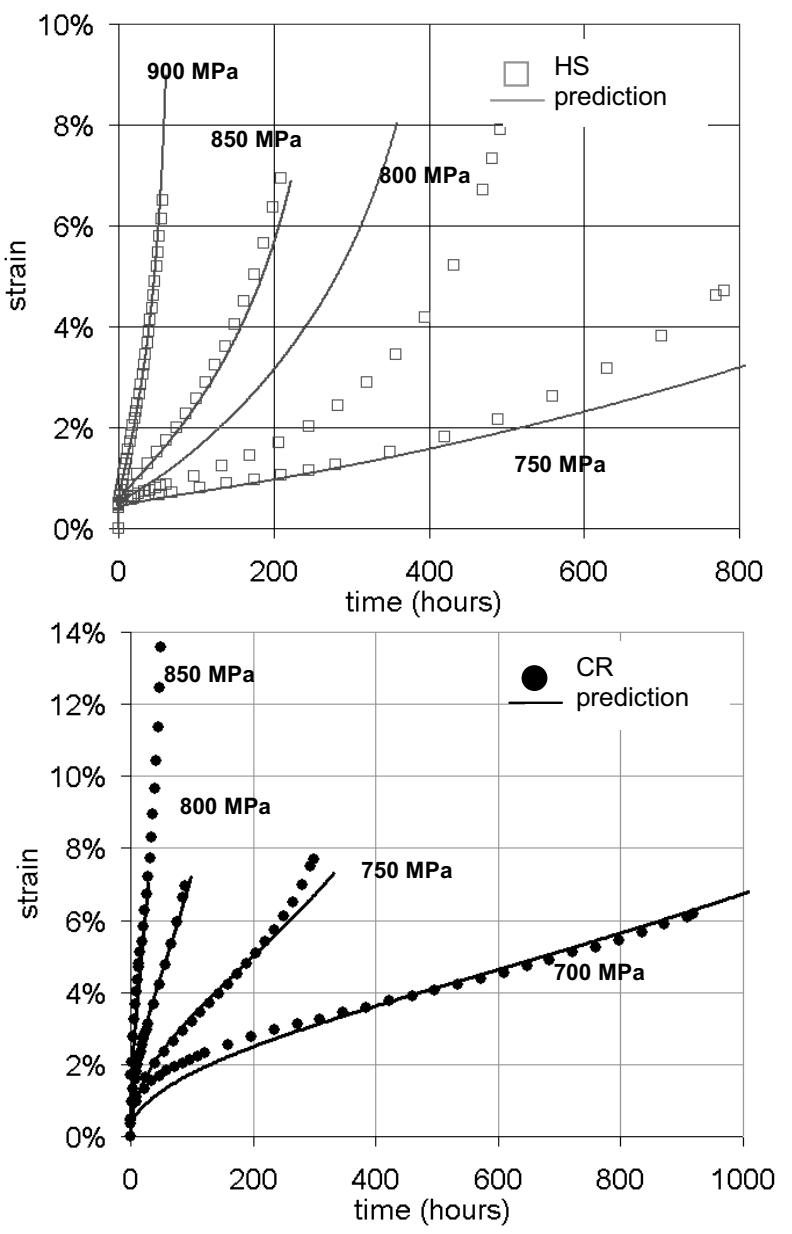

Figure 9 : Comparison of the McLean model predictions with experimental data for creep at $650^{\circ} \mathrm{C}$ of $\mathrm{P} / \mathrm{M} H I P-A$ Udimet 720 with HS and CR heat treatments.

\section{Conclusions}

1. $\mathrm{P} / \mathrm{M}$ Udimet 720 appears as a good candidate to produce large turbine disks for future direct cycle High Temperature Reactors.

2. The grain size and gamma prime distribution of $\mathrm{P} / \mathrm{M}$ U720 can be tailored to produce a long term creep resistant grade by selecting the proper HIP cycle and heat treatment.

3. HIPed coarse grain U720 has showed high temperature creep and tensile strength close to that of conventional $\mathrm{C} \& \mathrm{~W}$ grade.

4. The specific creep behaviour of P/M U720 is related to the $\gamma^{\prime}$ /dislocation interaction mechanisms, with either $\gamma^{\prime}$ particle shearing or overcoming by an Orowan mechanism.

5. The creep behaviour of $\mathrm{P} / \mathrm{M}$ Udimet 720 can be modelled by using McLean and Dyson approach with physically based damage parameters.

\section{Acknowledgements}

The CEA authors wish to acknowledge the fruitful cooperative spirit and technical support provided by Aubert\&Duval Holding. Particular attention is directed to J.Montagnon and G.Raisson who provided comments and advices on the feasibility of superalloy turbine disks. 


\section{References :}

1. R Couturier, C Escaravage, "high temperature alloys for the HTGR Gas Turbine: Required properties and development needs", IAEA Technical committee meeting, IAEA TecDoc 1238, (2000), 161-173.

2. H. Burlet, R. Couturier, S. Dubiez, "High temperature gas turbine for nuclear gas cooled reactors: materials needs and lifetime modelling", Advanced materials and processes for gas turbines, Ed. G. Fuchs et. al., TMS, (2003), 265-273.

3. J Montagnon, "private communication during the 2003 CEA Seminar on disk superalloys", 13-14 May 2003.

4. D.U. Furrer, H.J. Fecht, "Ni-based superalloys for turbine disks", JOM, vol.51, (1999), 14-17.

5. X. Pierron et. Al., "Sub-solidus process for conventional billet conversion", Superalloys 2000, Ed. T.M. Pollock et. al., TMS, (2000), 425-433.

6. D.R. Chang, D.D. Krueger, R.A. Sprague, "Superalloy powder processing, properties and turbine disk applications", Superalloys 1984, The metallurgical Society, AIME, (1984), 245-273.

7. R. Couturier et. al., "Matériaux de turbine pour réacteurs à caloporteur gaz, mise au point de la nuance U720 CIC à gros grains ”, (Report CEA DTEN-DR-2003-06, 2003).

8. F.E. Sczerzenie et. al., "Udimet alloy 720 ”, (Report SMC TR 88-002, 1988).

9. J. Davidson, "Process of grain enlargement in consolidated alloy powders ", US Patent 5.395.464, 1995.

10. S. Dubiez, "Comportement et endommagement d'un superalliage élaboré par Compression Isostatique à Chaud", $\mathrm{PhD}$ thesis, ENSMP, 2003.

11. E. Georges, "HIP-B torsion test results", (Aubert\&Duval Alliage letter GRD-EG-TC-04.005, 2004).

12. M. Maldini, V. Lupinc, " Modelling of the creep behaviour of a wrought Ni-based superalloy in a wide range of stress/temperature conditions", Proceedings of a conference "life assessment of hot section gas turbine conference" held at Heriot Watt, University Edinburgh, UK, (1999), pp. 109-118.

13. P.R Bhowal, E.F. Wright, E.L. Raymond, Metallurgical Transaction A, 21A, (1990), 1709-1717.

14. D. Locq, M. Marty, P. Caron, "Optimisation of the mechanical properties of a new $\mathrm{P} / \mathrm{M}$ superalloy for disk applications, Superalloys 2000, Ed. T.M. Pollock et. al., TMS, (2000), 395-403.

15. M. Mac Lean, B.F. Dyson, Eng. Mat. Technology, vol.122, (2000), 273-278. 
